\title{
Analysis of the Effect of Magnetostimulation on Viscoelastic Properties of Blood in Patients with Lasting Pain
}

\begin{abstract}
A. MarcinkowsKa-GapińsKA* AND P. KOWAL
Rheological Lab, Department of Neurology, Karol Marcinkowski University of Medical Sciences in Poznań

The aim of the current work was to analyze the influence of alternating magnetic field on the viscoelastic properties of blood in vivo in patients with lasting pain problems. Oscillatory techniques, also called the dynamic mechanical analysis, have been used in the current work to study the viscoelastic properties of blood. The blood samples were collected from patients of a neurological ward complaining about spinal cord and lower limbs pain. Altogether 25 patients took part in the study. A blood sample was collected from each patient twice: before the magnetostimulation and after five treatments. For each blood sample, the hematocrit value was measured using the standard method. Plasma viscosity and the complex whole blood viscosity were measured by means of a rotary-oscillating rheometer Contraves LS40. Magnetic field was generated by the instrument Viofor JPS and the magnetostimulation treatments were performed using different programs. The analysis of the results included estimation of the hematocrit value, plasma viscosity, complex whole blood viscosity and its components: viscous and elastic viscosity at four chosen amplitudes of the shear rate as a function of the applied treatment program. The results obtained in the study suggest that rheological properties of blood change depending on the applied magnetostimulation program.
\end{abstract}

DOI: 10.12693 /APhysPolA.125.A-24

PACS: 83.50.Ax, 83.60.Fg, 83.60.Bc, 83.80.Lz, 83.85.Vb, 87.50.C-

\section{Introduction}

Magnetostimulation is one of the new therapy methods. Magnetic field influences human organism causing different symptoms: headache, hyperactivity, fatigue, emotional tension, daily rhythm disturbances, etc. Fast changing magnetic fields are considered harmful, whereas weak and slowly changing magnetic fields are used in the diagnosis and in the treatment of many diseases such as: orthopedics, rheumatology, internal medicine, neurology, psychiatry, dentistry, and also psychiatry [1, 2]. Variable magnetic fields act on components of cell membranes exhibiting the properties of liquid crystal. They influence the depolarization of cells by introducing an additional force which changes positions of moving electric charges and induce electric potential in areas filled with electrolytes [1]. The effect of magnetic field on the hemorheological properties is not well known yet. One of the observed effects is a decrease of the whole blood viscosity [3].

One of the sources of magnetic field used in magnetotherapy and magnetostimulation is Vioform JPS system which generates pulses with different frequency, shape, and duration time, depending on the chosen program (P), applicator (M), and intensity (I). The shape of the pulse is adjusted to obtain biologically favorable effect involving creation of nuclear cyclotron resonance, electromagnetic resonance, and magnetomechanic resonance $[4,5]$. It has also been observed that the Viofor

*corresponding author; e-mail: margap@poczta.onet.pl
JPS device caused improvement in upper limb blood flow immediately after the first treatment. The measurements were performed before and after MF application, and the results were observed by the use of thermography [6]. It is believed that there is a direct relation between the rheological properties of systemic fluids and processes taking place in living organisms [7]. Rheological characterization of any material includes determining its two major properties: viscosity which defines its resistance to flow and elasticity which defines its resistance to deformation. Hemorheology is a part of rheology dealing with the flow properties of blood. The flow of blood depends both on rheological and physiological characteristics of the circulatory system and physicochemical properties of blood $[7,8]$.

Observing the blood flow in the smallest blood vessels one can see the erythrocytes deform when the vessel diameter reduces to the cell size. In turn, blood flow in large vessels is accompanied by the phenomenon of axial accumulation of red cells. A hemorheological study is primarily based on the blood viscosity measurements. In the case of non-newtonian fluids such as blood, viscosity is a function of the applied shear rate. The main factors determining blood viscosity are hematocrit value, erythrocytes aggegability, deformability and orientation in flow, plasma viscosity $\eta_{p}$ and shear stress $\tau$ [9]. According to the experiment of Chien, in the range of low shear rate $\gamma /$ the dominant phenomenon is the aggregation of erythrocytes, while in the range of high shear rate — their deformation [10].

Measurements of whole blood viscosity as a function of shear rate are performed by means of rotary rheometers, while blood plasma viscosity can be measured both by rotary and capillary viscometers because plasma is a 
Newtonian liquid. More information about blood rheology can be acquired from non-viscometric oscillatory measurements also referred to as the dynamical mechanical analysis (DMA) [9, 11, 12]. The operating principle is based on determination of the amplitude and phase of oscillations of a sample subjected to harmonic force with certain amplitude and frequency. In the oscillatory experiment one determines viscoelastic properties of the liquid under consideration by calculating the elastic modulus $G^{\prime}$, the loss modulus $G^{\prime \prime}$, and the complex viscosity

$$
\eta^{*}=\eta \prime+\mathrm{i} \eta \prime \prime
$$

where $\eta \prime$ and $\eta \prime \prime$ are the viscous and elastic components of the complex viscosity $\eta^{*}$, respectively, as a function of the circular frequency $\omega$, deformation amplitude $\gamma$, temperature $T$, and time $t$. Interpretation of the results obtained from DMA measurements for blood samples is usually qualitative [12-15]. Despite the fact that different mathematical models properly describe the viscoelastic properties of many non-Newtonian liquids such as polymer melts and colloidal suspensions, applicability of such models to blood samples turned out to be rather poor [15]. Therefore, in this study we restrict the analysis of DMA measurements to simple comparison of the viscous and elastic components of $\eta^{*}$ measured at different values of the shear rate amplitude $\gamma_{0}^{\prime}$.

\section{Materials and methods}

Measurements of the blood complex viscosity $\eta^{*}$ have been performed by means of a rotary-oscillating rheometer Contraves LS40 by applying constant frequency oscillations of frequency $f=0.5 \mathrm{~Hz}$ and decreasing shear amplitude $\gamma_{0}$. A group of 25 patients, 20 men and 5 women, aged 40 to 75 (average age 57), was included in the study. All of them suffered from lasting spinal cord and lower limbs pain. For each patient, two measurements were performed: first before the magnetostimulation therapy and the second one after 5 magnetostimulation sessions. As a source of the alternating magnetic field, the Viofor JPS device (produced by Med \& Life Poland) was used. The measurements of the complex blood viscosity were performed at the temperature of $37^{\circ} \mathrm{C}$. The blood was taken to vials containing $1.6 \mathrm{mg}$ EDTA per ml of blood. For each blood sample, the hematocrit value was measured using the standard method. Blood plasma viscosity was determined from a regular rotary measurement of a flow curve. The value of $\eta_{p}$ was calculated from the linear regression of the $\tau\left(\gamma^{\prime}\right)$ dependence.

\section{Results}

The oscillatory experiments allowed for estimation of the viscous and elastic components of the complex viscosity in the group of patients before and after a series of 5 magnetostimulation sessions. The values of the complex viscosity and blood complex components at several chosen values of $\gamma^{\prime}$ together with mean hematocrit values and plasma viscosities are presented in Table. Graphical representation of the complex viscosity shear rate dependence is shown in Fig. 1.

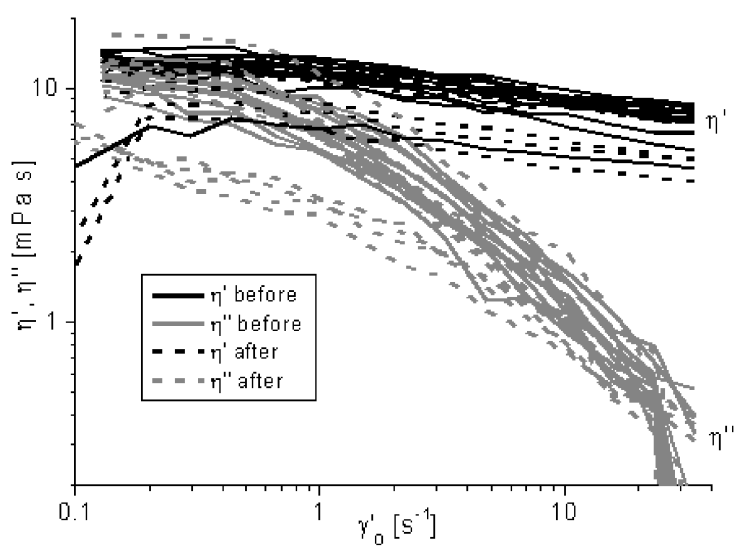

Fig. 1. Dependence of the viscous and elastic components of the complex blood viscosity on the amplitude of shear rate $\gamma \prime_{0}$ (for oscillation frequency of $0.5 \mathrm{~Hz}$ ) in the group of patients before and after magnetostimulation.

TABLE

The values of the complex viscosity and viscous and elastic components of the complex blood viscosity in the group of patients before and after magnetostimulation. Parameter $p$ indicates the limiting value of confidence level when the difference between the groups becomes statistically significant.

\begin{tabular}{|c|c|c|c|c|}
\hline \multirow{2}{*}{\multicolumn{2}{|c|}{$\begin{array}{l}\text { Rheological } \\
\text { parameter }\end{array}$}} & Patients before & Patients after & \multirow[t]{2}{*}{$p$} \\
\hline & & \multicolumn{2}{|c|}{ magnetostimulation $(n=25)$} & \\
\hline \multicolumn{2}{|c|}{ Hematocryte } & $0.45 \pm 0.03$ & $0.44 \pm 0.02$ & - \\
\hline \multicolumn{2}{|c|}{ value at $\gamma_{0}$} & $1.44 \pm 0.04$ & $1.40 \pm 0.07$ & - \\
\hline \multirow{4}{*}{$\begin{array}{l}\left|\eta^{*}\right| \\
{[\mathrm{mPa}}\end{array}$} & $0.2 \mathrm{~s}^{-1}$ & $17.4 \pm 0.8$ & $14.9 \pm 0.9$ & $<0.05$ \\
\hline & $1 \mathrm{~s}^{-1}$ & $14.8 \pm 0.6$ & $11.9 \pm 0.9$ & $<0.01$ \\
\hline & $10 \mathrm{~s}^{-1}$ & $8.9 \pm 0.3$ & $8.2 \pm 0.8$ & - \\
\hline & $20 \mathrm{~s}^{-1}$ & $8.1 \pm 0.3$ & $7.3 \pm 0.6$ & - \\
\hline \multirow{4}{*}{$\begin{array}{l}\eta^{\prime} \\
{[\mathrm{mPa} s]}\end{array}$} & $0.2 \mathrm{~s}^{-1}$ & $13.6 \pm 0.7$ & $12 \pm 1$ & - \\
\hline & $1 \mathrm{~s}^{-1}$ & $12.9 \pm 0.3$ & $10.9 \pm 0.9$ & $<0.05$ \\
\hline & $10 \mathrm{~s}^{-1}$ & $8.8 \pm 0.3$ & $8.1 \pm 0.8$ & - \\
\hline & $20 \mathrm{~s}^{-1}$ & $8.1 \pm 0.3$ & $7.2 \pm 0.6$ & - \\
\hline \multirow{4}{*}{$\begin{array}{l}\eta \prime \prime \\
{[\mathrm{mPa} s]}\end{array}$} & $0.2 \mathrm{~s}^{-1}$ & $11.0 \pm 0.8$ & $9 \pm 1$ & - \\
\hline & $1 \mathrm{~s}^{-1}$ & $7.3 \pm 0.3$ & $5.8 \pm 0.6$ & $<0.03$ \\
\hline & $10 \mathrm{~s}^{-1}$ & $1.4 \pm 0.2$ & $1.1 \pm 0.1$ & - \\
\hline & $20 \mathrm{~s}^{-1}$ & $0.77 \pm 0.07$ & $0.57 \pm 0.04$ & $<0.05$ \\
\hline
\end{tabular}

\section{Discussion}

The analysis of the measurements results proved that the hematocrit values in the group of patients were not significantly different in the statistical sense before and after the therapy. Such result allows to exclude the influence of hematocrit value on other estimated rheological parameters. 
The observed difference in the plasma viscosity (Table) between the results obtained before and after therapy (higher value before therapy) is not statistically significant. Decrease of plasma viscosity was observed before in a group of patients with cerebrovascular disease [16] and patients with ischialgia [17]. In in vitro studies, an increase was observed [18].

Comparison of the results obtained for the complex viscosity shows its decrease after magnetostimulation at two shear rate values (Table). The decrease of the viscous component $\eta^{\prime}$ of the complex blood viscosity is significantly different for one shear rate value (Table). Comparison of the elastic components of the complex viscosity for the patients before and after magnetostimulation sessions shows higher values before the therapy at two shear rate values (Table I). Such result may indicate that magnetostimulation increased red cell deformability in the group of patients with lasting pain. Results obtained from rotary measurement show a decrease of blood viscosity after magnetotherapy [16-18] which corroborates the thermography studies [6].

\section{Conclusions}

Comparison of the complex viscosity and the obtained viscous and elastic components of the complex blood viscosity in the group of patients before and after magnetostimulation shows a significant decrease of both components after 5 magnetostimulation sessions.

\section{References}

[1] J. Pasek, R. Mucha, A. Sieron, Physiotherapy 4, 3 (2006).

[2] A. Sieron, R. Brus, R. Szkilnik, A. Plech, N. Kubanski, G. Cieslar, Bioelectromagnetics 22, 479 (2001).

[3] R. Tao, K. Huang, Physical Rev. E 84, 011905 (2011).
[4] A. Sieroń, Zastosowanie pól magnetycznych w medycynie, Ed. A. Sieroń, $\alpha$-medica press, Bielsko-Biała 2002.

[5] M.B. Pecyna, Wolnozmienne pola magnetyczne w badaniach psychofizjologicznych, Wydawnictwo Akademickie "Zak", Warszawa 2001.

[6] P. Kowal, A. Marcinkowska-Gapińska, in: Some aspects of medical physics - in vivo and in vitro, Eds.: Z. Drzyzga, K. Ślosarek, HARD Publishing Company, Olsztyn 2010, p. 59.

[7] L. Dintenfass, Biorheology 27, 149 (1990).

[8] Abbreviations of periodica H. Schmid-Schönbein, H. Rieger, T. Fischer, Angiology 31, 301 (1980).

[9] D. Lerche, H. Bämler, W. Kucera, W. Meier, M. Paulitschke, in: Physical Characterization of Biological cells. Basic research and clinic relevance, Eds.: W. Scütt, H. Klinkmann, I. Lamprecht, T. Wilson, Verlag Gesundheit, Berlin 1991, p. 189.

[10] S. Chien, Science 168, 977, (1970).

[11] B. Sandhagen, Acta Universitatis Upsaliensis, Uppsala 1988.

[12] A. Marcinkowska-Gapińska, F. Jaroszyk, L. Kubisz, Sci. Proc. Riga Tech. Univ. Ser. 6, Transport and Engineering, 2002, p. 159.

[13] D. Lerche, G. Vlastos, B. Koch, M. Pohl, K. Affeld, J. Phys. III France 3, 1283 (1993).

[14] H. Chmiel, I. Anadere, E. Walitza, Biorheology 27, 883 (1990).

[15] G.B. Thurston, Biophysical J. 12, 1205 (1972).

[16] P. Kowal, A. Marcinkowska-Gapińska, Neuroskop 7, 135 (2005).

[17] A. Marcinkowska-Gapińska, P. Kowal, F. Jaroszyk, in: Biofizyka a medycyna, Uniwersytet Medyczny im. Karola Marcinkowskiego w Poznaniu, Poznań 2012, p. 46.

[18] A. Marcinkowska-Gapińska, H. Nawrocka-Bogusz, BioMed Research International, 490410 (2013). 